\title{
ALTO PORCENTAJE DE LA POBLACIÓN LABORAL JOVEN DE LIMA DESCONOCE QUE SUS AHORROS EN LAS AFP LE SERÁN DEVUELTOS AL MOMENTO DE SU JUBILACIÓN CON MENSUALIDADES MUY INFERIORES A SU ÚLTIMO SUELDO PERCIBIDO
}

\author{
HIGH PERCENTAGE OF YOUNG PEOPLE OF LIMA WORK, YOU KNOW YOU'RE SAVINGS IN THE AFP, \\ WILL BE RETURNED AT THE TIME OF HIS RETIREMENT WITH VERY LOWER MONTHLY TO YOUR \\ LAST SALARY EARNED \\ Dr. Juan Manuel Barreda Guerra* \\ Jumabague@yahoo.es
}

[RECEPCIÓN: JULIO DEL 2014/CONFORMIDAD: SETIEMBRE DEL 2014]

\begin{abstract}
RESUMEN
El planteamiento de la problemática legal, económica, social y política que ha originado la Ley del Sistema Privado de Pensiones en Perú, a veintidós años de su creación, está cargada de insatisfacciones en la masa laboral peruana, debido a que, en aquella época de los 90, para la fácil implementación del Decreto Ley N 25897 al cuerpo legal de las leyes laborales del país, se utilizó publicidad basada en desinformación, ambigua y engañosa, la cual generó falsas expectativas en los derechos del ahorrista. De otro lado, al implantarse el modelo de las AFP dentro de un gobierno autócrata e inquisidor en la década de los 90 , se cometieron muchas extorsiones, amenazas y abusos contra los trabajadores, incluso se falsificaron firmas de los trabajadores para afiliarlos a una determinada AFP, vale decir que la fuerza de ventas utilizada por el modelo contenía gánsteres.

Hoy los trabajadores del Perú tienen la oportunidad de advertir que el Gobierno de los años 90 del Perú les mintió y los mantuvo desinformados por muchos años; los trabajadores del país pueden ver claramente los resultados del engaño por el Estado, en la forma, manera y modo de los rendimientos de sus dineros entregados de modo forzoso y coercitivo a terceras personas jurídicas por años, para obtener beneficios financieros paupérrimos, en relación con los que gozan los inversionistas en las AFP. Razón por la que hoy sienten la necesidad de rescatar el derecho a sentarse a demandar al Estado el replanteamiento de la ley, en lo referente a la obligatoriedad del ahorro por el ciudadano trabajador en el sistema privado, sistema mal llamado de pensiones, que no tiene equidad en la distribución de beneficios de las rentabilidades obtenidas entre los actores generadores de enormes masas de dinero en condiciones de "ahorro". Los ahorristas no podrán tener ningún reclamo para la disponibilidad de sus ahorros hasta que transcurran más de treinta (30) años. El sistema se arroga el derecho de decirle al propietario del dinero, cuántos años vivirá y el modo y número de cuotas para la devolución de su dinero, a lo cual debemos añadir una serie de incoherencias para la disponibilidad
\end{abstract}

\footnotetext{
* Doctor en Ciencias Administrativas. Docente asociado de la Facultad de Ciencias Administrativas. Ex Perito Judicial en Administración de la Corte Superior de Justicia de Lima. Past Decano Nacional del Colegio de Licenciados en Administración del Perú. Ex Director Académico. Actualmente Director del Instituto de Investigación de la facultad de Ciencias Administrativas de la UNMSM.
} 
del dinero por el trabajador ahorrista. Los ahorristas participantes requieren y plantean, tratar el tema con el Estado, que se hace cómplice en el abuso esclavizador sobre el derecho a la libre disponibilidad de la propiedad privada de los ahorros de la masa trabajadora del país y la negativa a compartir en equidad las bondades y beneficios de las rentabilidades obtenidas, y la transparencia que debe brindar la ley a los ahorristas.

Palabras claves: Previsionalidad del trabajador, ahorro forzoso, decreto ley, coerción.

\begin{abstract}
The approach of the legal, economic, social and political problems that caused the Law of the private pension system in Peru to twenty-two years of its creation is fraught with dissatisfaction in the Peruvian labor force, according to which, at the time of 90, for easy implementation of Decree Law 25897 legal body of labor laws in the country, based on misinformation, ambiguous and misleading advertising was used, which generated the false expectations on the rights of the saver. On the other hand the implemented model AFPs within an autocrat and inquisitor government in the 90s, many extortions, threats and abuses workers were committed, including workers' signatures were falsified to affiliate to a particular AFP, ie that the sales force used the model was full of gangsters.

Today Peru workers have the opportunity to warn that the state and government of the 90's Peru lied and kept uninformed for many years; workers in the country today can clearly see the results of deception by the state, in the form, manner and method of performance of its funds given to forced and coercive another way for years, to get penniless financial benefits in relation to enjoyed by investors in the AFP. Reason for today feel the need to rescue the right to sit and rethink the law of compulsory savings by working citizen who obliges with no equity in the distribution of benefits among the actors involved in the fate of the savings workers in the country who propose to address the issue of labor savings to the state, and the advantages and benefits that the law should provide the saver.
\end{abstract}

Keywords: Previsionalidad Worker, Decree Law, coercion, Forced savings.

\section{INTRODUCCIÓN}

En el desarrollo de esta investigación, que constituye un tema de alta sensibilidad, y enorme preocupación de todos los trabajadores de nuestro país y al mismo tiempo es una dimensión en la que se da una serie de controversias de tipo legal, constitucional, laboral, económico, social y político, que la determinan como altamente polémica e inclusive controversial, he visto por conveniente dividirla en dos fases o etapas. En esta primera, etapa considero oportuno clarificar el concepto de previsionalidad social orientada hacia la jubilación y su real justificación social sin límite exploratorio alguno y a la obtención de información relevante que oriente la investigación bajo asideros reales y válidos en el derecho inalienable de la libertad universal del hombre, capaz sobre sus propiedades y con decisión sobre qué desea hacer con ellas; en buena cuenta, analizar y tratar de entender la base legal y llegar a encontrar el verdadero espíritu de las leyes previsionales, que hoy lo obligan a ser ignorante y torpe sobre lo que debe hacer para su vejez. Esta búsqueda ha resultado siempre difícil, hasta imposible en nuestro país, así como conocer si estas leyes mantienen en equidad los beneficios entre los actores intervinientes en el sistema como son el Estado, el empresario y el ahorrista.

Asimismo, la investigación ha requerido evaluar una dimensión mayor del contexto económico social y del tiempo transcurrido desde que se crea el modelo en Chile en la década de los 90 y se extiende a otros países de la región de manera idéntica a su modelo primigenio, con los problemas económicos y sociales que se le presentan al modelo, que origina el descontento de los trabajadores argentinos, colombianos, chilenos y peruanos, y su quiebra en dos de estos países.

Para tratar de entender lo primero, citaré a Milton Friedman': "Hablando de etiquetas engañosas... el Seguro Social es la mayor falsedad. No es social ni seguro... Es un programa que impone malos impuestos para proveer beneficios injustos".

\footnotetext{
1 Milton Friedman. ¿QUÉ ES LA SEGURIDAD SOCIAL? Economía política internacional con ejemplos de América Latina. Premio Nobel en economía 1976 - Viena.
} 
Históricamente, el esquema de la seguridad social previsional en nuestro país se basó en un "sistema de reparto"; es decir, los aportes al sistema por quienes están trabajando hoy cubren la pensión previsional de los jubilados en el momento. De este modo se han sucedido generacionalmente los sueldos de las planillas de los jubilados. Los aportantes actuales confían en que la siguiente generación hará lo mismo.

El "reparto" aparentemente conlleva un pacto intergeneracional que podemos entender de este modo: Una determinada generación de trabajadores en un "momento en el tiempo" entrega sus aportaciones para ser repartidas entre quienes están jubilados hoy, a cambio de que la siguiente generación de trabajadores financie la pensión que ellos recibirán en el futuro y esperan que esa pensión que reciban tenga el mismo poder de compra del dinero que han venido entregando a lo largo del tiempo de sus aportaciones.

Según Artur Damm, al preguntarse qué es la seguridad social, responde de este modo: En el menos malo de los casos, es el gobierno que obliga al gobernado a beneficiarse a sí mismo, cuando le exige, por ejemplo, ahorrar para su retiro. En el peor, es el gobierno que obliga a parte de los gobernados a beneficiar a la otra parte, cuando les cobra impuestos a los primeros para, por ejemplo, pagar la atención médica de los segundos. En el primer caso, el Gobierno trata al gobernado como si fuera un niño incapaz de responder por sus actos, al que hay que obligar a que se cuide. El Estado y su gobierno no toma en cuenta a quien le impone y obliga a "Cuidarse y prever" por su mañana. De este modo, no interesa el nivel de preparación y formación del ciudadano, es posible que sea el rey de las finanzas y los negocios en el país o que sea un ciudadano muy culto y preparado y, justamente por ese motivo, se interesa nada por el Estado y su preocupación por su vejez. El Estado, para ese ciudadano, nunca ha sido algo creíble; Es considerado como una dimensión de ciudadanos elegidos para que tengan la oportunidad de demostrar a sus connacionales que son verdaderamente ineptos e incapaces, con gran habilidad para corromperse y delinquir, sin dejar de reconocer que en dicha dimensión existe honrosas excepciones de ciudadanos inteligentes, capaces y probos. En el segundo caso, los gobiernos que deban sucederse hasta lograr implantar el sistema de previsión social deberán sucederse, por lo menos, hasta en cinco periodos de gobierno para implantar el modelo económico en el que se trata al contribuyente como esclavo, siendo este el típico concepto y uso de criterios de la ingeniería económica, "ciencia" en la cual el ser humano no puede ser libre, sino un esclavo al que se le obliga a trabajar en beneficio de alguien más, obligándolo a entregar, por el cobro de impuestos, parte del producto de su trabajo. En ambos casos, el Gobierno abusa de su poder, obligando al ciudadano a entregar, ya sea a su favor o en beneficio de alguien más, parte del producto de su trabajo, pues si no existiera esa obligación, el ciudadano no la entregaría.

\section{¿DÓNDE, CUÁNDO Y CÓMO NACE EL SISTEMA DE LAS AFP?}

En 1980 en Chile, año de reforma previsional ${ }^{2}$, se diseña el nuevo sistema de fondo de pensiones (dictado por la Ley $\mathrm{N}^{\circ} 3.500$ ), que esta vez iba a ser administrado por entidades privadas de capitalización individual. La ley se da dentro de un tiempo histórico en el que los ciudadanos chilenos no gozaban de democracia y, por lo tanto, el pueblo se encontraba amordazado y amenazado de cárcel ante cualquier tipo de expresión opositora a la voluntad política del régimen totalitario de ultra derecha extrema del general Augusto Pinochet, quien gobernó de la mano con el gran capital chileno y sus empresarios hambrientos de recursos económicos y financieros para generar mayor riqueza para estos grupos dominantes, aliados al gobierno "revolucionario", al cual le han sucedido gobiernos "democráticos" que, hasta hoy, no muestran la menor intención de cambiar el sistema, aun cuando Chile muestra ser el país con un alto promedio en el índice de Gini en la distribución de su riqueza. Vale decir que después de 33 años de implantación de las AFP en Chile, los trabajadores advierten que pasaron su vida trabajando y aportando para una vejez no digna, pero sí enriquecieron a una minoría de empresarios siempre al poder de turno.

\section{¿CUÁNDO Y CÓMO NACE EL SISTEMA DE LAS AFP EN PERÚ?.}

El Sistema Privado de Pensiones (SPP) fue creado en Perú el 6 de diciembre de 1992, a través del Decreto Ley 25897, durante el gobierno

2 http://fondosdepensiones.webnode.es/historia-de-las-afp/ 
del presidente Alberto Fujimori y el ministro de Economía Carlos Boloña, quienes aliados con fuertes grupos de empresarios con altos intereses en conseguir recursos económicos y financieros para dar apalancamiento financiero a sus bancos y empresas, podían constituir una AFP con tan solo $\mathrm{S} / 500,000$ y hacerse rápidamente de millones de millones de soles de sus ahorristas, captados bajo un bombardeo de publicidad engañosa que nadie pudo controlar en aquellos momentos por cuanto lo que se ofrecida era a futuro, nadie tenía elementos de juicio como para poder demostrarle al nuevo sistema que eso no funcionaría. Es bueno recordarle al lector que el tipo de gobierno que nuestro país tenía en ese entonces fue dictatorial e inquisidor, el cual se desborda en el mayor ejercicio de la coerción estatal al ciudadano y el imperio de la corrupción y el totalitarismo fujimontesinista que todos conocemos. En este sentido, tanto la aplicación del sistema de las AFP en Chile como en Perú, nació bajo la misma estrella del totalitarismo y coerción al trabajador. En Perú el expresidente Fujimori se encuentra en la cárcel y el exministro del "milagro" peruano Carlos Boloña se encuentra prófugo de la justicia.

Era el año 93 cuando Alejandro La Jara -entonces de 47 años, 23 de ellos laborando en la empresa Castelano- recibió la visita ${ }^{3}$ de una representante de una AFP, quien le informó de las bondades de (SPP) y la inminente quiebra del Sistema Nacional de Pensiones (SNP). "Sin pensarlo mucho y con la esperanza de recibir una pensión mejor, me afilié a la AFP. Hoy me arrepiento de aquella decisión, pues estoy a punto de cumplir 65 años y no puedo jubilarme porque mis aportaciones al SPP son insuficientes", señala La Jara.

Pedro Córdova es otro trabajador que a inicios de los 90 se afilió a una AFP, pero a diferencia de La Jara a él no le dieron la opción de elegir, sino que simplemente lo obligaron a trasladarse al SPP, pues, de lo contrario, sería despedido. "En setiembre cumpliré 65 años y pese a haber trabajado durante 40 años, la ONP no me reconoce los 25 años que aporté al SNP. En la AFP me han dicho que sin el reconocimiento del bono recibiré una pensión de S/.100 hasta agotar mi fondo", expresa con desolación.
Alejandro y Pedro son parte de los miles de trabajadores perjudicados por una reforma que implementó la dictadura fujimorista y en la cual -una vez más- no primó el interés de la nación.

En 1992, el lobby de Carlos Boloña, entonces ministro de Economía, fue pieza clave en la Ley de Creación del Sistema Privado de Administración de Fondos de Pensiones (25897). Actuó, incluso, en contra de capitales peruanos, pues promovió una ley que prohibió a los bancos nacionales participar en la formación y gestión de las AFP.

Luego de promulgar la legislación de las AFP, Boloña pasó a presidir el directorio de AFP Horizonte. Quedó en evidencia, entonces, que las desmedidas ventajas que se les había otorgado a las AFP no eran gratuitas.

\section{DERECHO A LA DESAFILIACIÓN}

Fueron los primeros jubilados de las AFP -que durante su vida laboral tuvieron ingresos mínimos- quienes descubrieron el engaño al cobrar pensiones ínfimas y menores de las que recibían sus compañeros que se mantuvieron en el SNP. Peor aún, muchos fueron informados recién que su pensión se acabaría cuando su fondo expirara. La renta vitalicia y pensión mínima son medidas que se implementarían luego.

\section{DERECHO A DESAFILIARSE}

La Asociación Departamental de Azucareros de Lambayeque denunció que las AFP daban pensiones de S/. 300, S/. 400 y S/. 500 a sus afiliados, cuando la ONP otorgaba de S/. 800 a S/. 1500 mensuales. Por ello, exigieron el derecho a desafiliarse del Sistema Privado de Pensiones. Sin embargo, no fue hasta el 2007 que se aprobó la ley de libre desafiliación de las AFP.

\section{¿CUÁNDO Y CÓMO SE CREAN LAS AFP EN URUGUAY?}

En un artículo publicado por Daniela Zumino ${ }^{4}$ en el diario El Mercurio el 23 de abril del 2007 se hace referencia a la ley aprobada en el Uruguay en 1995 Ley 16713, que establece que "el sitema previsional que se crea se basa en un régimen mixto, que recibe las contribuciones y otorga las prestaciones en forma combinada", de esta mane-

\footnotetext{
3 ROCÍO MALDONADO. Diario La República. Afiliaciones indebidas a las AFP fueron un gran negociado del fujimontesinismo. Perú 07 de mayo del 2011.

4 DANIELla ZAMINO. Diario El Mercurio. Chile 23 de Abril del 2007.
} 
ra los aportantes recibiran una doble jubilación. En tal sentido, una parte del aporte irá al Banco de Previsión y la otra producirá un resultado financiero para el aportante, produciéndose de este modo un doble resultado económico para el trabajador.

\section{¿CUÁNDO Y CÓMO SE CREAN LAS AFP EN ARGENTINA?}

En 1994 el parlamento Argentino aprobó el sistema de retiro por capitalización sistema ${ }^{5}$, en el que operarán diez compañías controladas por bancos y aseguradoras de capitales europeos, estadounidenses y argentinos, con 9.5 millones de afiliados (Buenos Aires, EFE).

\section{¿CUÁNDO Y CÓMO SE CREAN LAS AFP EN COLOMBIA?}

El debate de la reforma pensionable en Colombia fue arduo y prolongado ${ }^{6}$. Se extendió desde principios de 1992 y solo se aprobó en diciembre de 1993. Fueron muchas las instancias de discusión a nivel técnico, político y académico. Aquí vale la pena destacar el papel que jugó el Presidente Gaviria, quien participó activamente en el debate técnico y fue decisivo en las negociaciones a nivel político.

El Gobierno propuso al Congreso una sustitución completa del régimen público por el de capitalización individual, al estilo chileno, pero esta no fue aceptada. Se llegó finalmente a una transacción política que dio como resultado un sistema híbrido en el que conviven y compiten dos regímenes, uno administrado por el anterior monopolio estatal y el otro por administradoras privadas de fondos de pensiones. El primero se mantiene como un régimen de prima media con prestación definida, mientras que el segundo es un régimen de capitalización individual.

\section{CUÁLES SON LOS RESULTADOS DE LA APLICACIÓN DEL SISTEMA DE LAS AFP EN LA ADMINISTRACIÓN DE LOS FONDOS DE PENSIONES EN LOS PAÍSES DE LA REGIÓN SUDAMERICANA EN LOS QUE SE IMPLANTÓ EL SISTEMA}

Los resultados en estos veinte a treinta años de implementación de las AFP en países Sudamericanos podemos tratarlos en dos niveles; el primero, en los resultados obtenidos en la economía local en cada país en el que se instaló el sistema; y el segundo, en las mejoras de las pensiones que han obtenido los ciudadanos jubilados en cada uno de los países y las expectativas que tienen los trabajadores sobre el sistema.

En cuanto al primer aspecto, se puede decir que el impacto que han tenido los fondos de pensiones administrados en la economía interna de cada país ha sido positivo y muy beneficioso para los mercados de capitales locales, financiamientos de obras públicas, inversión y contribución al PBI local. Han sido bastantes significativos en los países de la región, a excepción de Argentina, donde la administración de los fondos de las AFP tomaron forma de deuda privada y pública, lo cual quebró el sistema y dejó sin pensiones a los jubilados argentinos, teniendo el gobierno que nacionalizarlo.

En Chile, en la actualidad existe todo un movimiento organizado que cuenta, hasta junio del 2014, con medio millón de firmas y presiona al gobierno de la presidenta Michelle Bachellet solicitándole la anulación del sistema por considerarlo injusto y coercitivo para el trabajador. En virtud a esta situación, se puede advertir la fuerte tendencia del descontento nacional sobre el sistema después de treinta años de implementado y de operaciones que han permitido enorme fortalecimiento y beneficio a la economía chilena con dineros de los trabajadores; sin embargo, los aportantes se consideran no protegidos ni beneficiados por el sistema en su calidad de vida en su etapa no productiva.

En Colombia, el sistema no pudo avanzar hasta su ofrecimiento de llegar a cubrir mayor porcentaje de provisionalidad de la población económicamente activa (PEA). A lo largo de dos décadas de implementación no ha podido superar su clásico $35 \%$ de cobertura, con lo cual los trabajadores colombianos consideran que ha fracasado como sistema y solo beneficia a grupos de intereses inversionistas y a la macroeconomía, mas no a las expectativas de vida de los colombianos luego de haber cumplido su ciclo productivo social laboral.

EN ARGENTINA GOBIERNO INTERVIENE AFP POR ESTAR QUEBRADAS Y DEJAR SIN PENSIÓN A JUBILADOS

\footnotetext{
5 http://blog.pucp.edu.pe/member/817/blogid/741

6 Cristina Isabel Arrieta Mendoza. Las reformas del sistema pensional colombiano. Colombia- Diciembre 2011
} 
A nadie se le escapa que las "terapias de choque" aplicadas por De la Madrid, Pinochet, Salinas, Menem, Fujimori y Zedillo son posibles debido, en gran medida, a la notable subordinación de las economías de estos países ${ }^{7}$ a las clases dominantes del sistema capitalista internacional, y muy en particular al capital financiero y sus "perros guardianes", como llama Atilo Borón al Banco Mundial y el Fondo Monetario Internacional. No se trata de una mera "dependencia externa", sino de una articulación compleja, y cada vez más íntima, entre los bloques de poder existentes en nuestros países (los millonarios de la revista Forbes) y los amos financieros del mercado mundial, que hizo que los gobernantes latinoamericanos aplicaran en forma diligente el evangelio económico que los intelectuales orgánicos de Wall Street crearon para remodelar al mundo en función de los intereses trasnacionales: El llamado "Consenso de Washington".

Resulta paradójico que para crecer y consolidarse, la doctrina neoliberal dependa fundamentalmente del Estado al que estigmatiza, y no simplemente de los sacrosantos "principios de mercado". La historia reciente demuestra, como afirma el politólogo estadounidense James Petras, que la política de ajuste se impone gracias a la violencia y a la represión, y no es el resultado de la superioridad intrínseca del libre mercado.

Diario La República: El Gobierno de Argentina anunció que impulsará una reforma legal ${ }^{8}$ para traspasar millonarios fondos de pensión administrados por entidades privadas al sistema estatal de jubilaciones en virtud a su quiebra. La presidenta argentina, Cristina Fernández, firmó el proyecto de ley que enviará al parlamento para concretar esta reforma y tranquilizar a los ahorristas coercionados. El plan oficial supone el traspaso al Estado de la cartera de fondos gestionada por las administradoras de fondos de jubilación y pensión (AFJP) por 98,000 millones de pesos (unos 30,600 millones de dólares).

\section{POR QUÉ FRACASARON LAS AFP EN COLOMBIA}

La reforma pensional de la Ley 100 de 1993 fracasó en su intento de elevar la población efec- tivamente cubierta ${ }^{9}$, pues ha permanecido en la franja del 33\%-35\% de la PEA, tras dos décadas de su implementación. Las proyecciones pensionales que hicieron Schmidt Hebbel (entonces en el Banco Mundial), Ulpiano Ayala (en el MHCP), Juan Luis Londoño (en el DNP) y Eduardo Lora (en Fedesarrollo), entre otros, prometían que dicha cobertura llegaría a la franja del $45 \%-60 \%$ de la PEA, siguiendo la tendencia de Chile ${ }^{10}$, una vez que se ajustaba por patrones de ingreso per cápita y de "cultura" de lo formal.

Por eso nos ha sorprendido que el propio Lora (ver artículo en revista Dinero del 5 de mayo de 2014) ahora diga que el sistema de AFP ha sido un gran fracaso, cuando el problema de la informalidad NO puede ser atribuible a la existencia de las AFP. Por el contrario, la creación de mecanismos de mercado, como las AFP, ha ayudado a impulsar la formalización laboral y tributaria (pues sin ella no se puede crecer). Lo que no se menciona es que ha existido otra serie de bloqueos a la formalidad del mercado laboral, como en casi toda América Latina.

\section{EN CHILE ORGANIZACIONES CONTRA AFP JUNTAN MÁS DE 500.000 FIRMAS EN 11 MESES PARA EXIGIR TÉRMINO DEL SISTEMA}

El movimiento Aquí la Gente, la Corporación Nacional de Consumidores y Usuarios, Conadecus y la Asociación Nacional de Pensionados recolectan desde hace nueve meses las firmas de personas que apoyan el fin del sistema de Administradoras de Fondos de Pensiones, AFP.

Las diferentes agrupaciones demandan la derogación del decreto que creó en 1980 el modelo de capitalización individual de las AFP y que se instaure un sistema estatal de pensiones.

El presidente del movimiento Aquí la Gente, Ernesto Medina, señaló que quieren que exista libertad de afiliación para todas las personas y que sean ellas quienes elijan si prefieren un sistema privado o público.

Las distintas organizaciones sociales han logrado, en nueve meses, reunir más de medio millón de firmas, las que pretenden aumentar y entregar el 11 de mayo a la presidenta Michelle

\footnotetext{
$7 \mathrm{http} / / /$ www.hechohistorico.com.ar/Trabajos/Valores_Socioculturales/lecvmx118.html.

8 mbermudezhttp://blog.pucp.edu.pe/member/817/blogid/741

9 SERGIO CLAVIJO VERGARA Especial para Diario del Huila. Colombia. 
Bachelet para que elabore un proyecto de ley sobre la materia.

No caben dudas de que el sistema AFP ha sido un FRAUDE. Sin embargo y siendo jubilado de AFP, no es la solución volver al sistema antiguo como estaba concebido. Creo que deberían crearse EMPRESAS SIN FINES DE LUCRO TIPO CAJA DE COMPENSACIONES.

Entre las correcciones no se debería PAGAR NINGUNA COMISION.

\section{ES EL DINERO DE LOS TRABAJADORES Y NO SE DEBE PAGAR POR PRESTAR SU DINERO}

El financiamiento de estas empresas debe estar en directa relación con las rentabilidades que generen los fondos.

La otra arista muy importante a determinar es que las pensiones no se calculen sobre el capital acumulado, ya que las rentabilidades de los sistemas de ahorro NUNCA darán un capital suficiente que nivele el sueldo en actividad,

Por lo anterior, debe crearse una segunda cuenta DENOMINADA SOLIDARIA, la cual debe complementar la renta a las personas ahorristas.

\section{CUÁL ES EL BALANCE DE ACEPTACIÓN O RECHAZO SOBRE EL SISTEMA DE LAS AFPs EN LA REGIÓN}

\section{Cuadro $\mathrm{N}^{\mathrm{O}} \mathrm{I}$}

Comparación de niveles de aceptación y rechazo a las AFP por sus respectivas PEA en la región sudamericana.

\begin{tabular}{|c|c|c|}
\hline PAÍS & ACEPTACIÓN & RECHAZO \\
\hline Chile & & $\mathrm{X}$ \\
\hline Perú & & $\mathrm{X}$ \\
\hline Uruguay & $\mathrm{X}$ & \\
\hline Colombia & & $\mathrm{X}$ \\
\hline Bolivia $^{*}$ & $\mathrm{X}^{*}$ & \\
\hline Argentina & & $\mathrm{X}$ \\
\hline TOTAL & 2 & 4 \\
\hline
\end{tabular}

Fuente: Elaboración propia. * En Bolivia la implementación solo lleva seis años, es muy prematuro el tiempo para evaluar beneficios para los trabajadores, empero se puede decir que es crónica de una muerte anunciada para el sistema establecido para los trabajadores. Sin embargo, sí se ha obtenido beneficios para la economía.
En Bolivia la implantación del sistema de las AFP tiene tan solo seis años, tiempo muy corto para que los aportantes puedan solicitar resultados al sistema. Empero, el sistema sí está cargándose de enorme cantidades de recursos económicos. Algo exactamente igual sucedió en todos los países de la región en los que se implantó el sistema de las AFP. La publicidad que desplegaron las AFP en Perú tuvo un histórico presupuesto ejecutado, superior a $\$ 12^{\prime} 000,000.00$, en el año de la campaña de lanzamiento, cifra que fue verdaderamente exorbitante en aquellos años, con una campaña publicitaria de bombardeo a través de todos los medios de comunicación existentes, algo abrumador e impactante por la cantidad de mensajes en los que se ofrecían mejores niveles de vida para los futuros trabajadores jubilados de nuestro país. Los niveles de información en la publicidad que se emitía a través de sus mensajes omitían mucha información que las AFP debieron brindar a los trabajadores, pues ese no era el objetivo de la publicidad. El objetivo para cada AFP era captar la cantidad de afiliados que determinaba su punto de equilibrio y superarlo ampliamente, dado que desde ese punto comenzaba el enorme beneficio económico y financiero para cada AFP que se formó con un capital de S/. 500,000. Hoy, al haber transcurrido más de dos décadas de implantación del sistema, los trabajadores del Perú ven que las AFP hicieron publicidad engañosa y cada vez es mayor el rechazo de la población económicamente activa del país al sistema. Como advierte el cuadro $\mathrm{N}^{\circ} \mathrm{I}$, se observa que de seis países en la región sudamericana en los que se implantó el sistema de las AFP, después de dos décadas de operaciones, el $66 \%$ de estos países las rechaza, vale decir que su población económicamente activa hoy se da cuenta que lo ofrecido por las AFP no era cierto. Los ahorristas reciben miserias por sus largos y prolongados aportes y la disponibilidad de sus ahorros no es posible, porque la ley que avaló su implantación es coercitiva y antidemocrática. El ciudadano aporta a la AFP su dinero ahorrado y que en amparo de sus derechos debe disponer libremente mientras lo necesite en su vida productiva. Si consideramos a Bolivia, país en el que los trabajadores aún no pueden darse cuenta de que el sistema de las AFP no les dará a la vuelta de veinte años el bienestar que hoy les ofrece, porque realmente no tienen como probarlo, dado que por lo reciente de la 
implantación del sistema de las AFP aún no tienen trabajadores que reciben pensiones y ver si en realidad se cumplen los ofrecimientos. En virtud de esta realidad, podemos decir que en el $80 \%$ de los países en los que se implantó el sistema de las AFP hace veinte años, hoy es rechazado totalmente por más de cincuenta millones de trabajadores en la región sudamericana.

\section{¿CUÁLES SON LAS EXPERIENCIAS, PREOCUPACIONES Y EXPECTATIVAS DE LOS TRABAJADORES EN PERÚ?}

A veintidós (22) años de implantación del sistema de las AFP en Perú, por las experiencias de los trabajadores en aspectos de devolución de sus ahorros bajo denominación legal no válida de "Pensión de jubilación", se siente que es mucho lo que se tiene que reclamar al Estado, entendiéndose con ello al gobierno de turno que le corresponda absolver las preocupaciones e interrogantes de los trabajadores del país.

En primer lugar, se trata de una imposición y coerción a los trabajadores del país por un gobierno inquisidor y antidemocrático en la década de los noventa, en la que se obliga al ciudadano trabajador, por ley, a ahorrar una cantidad de dinero de sus ingresos, fijada por el Estado, para entregarla a su cuenta individual en el denominado fondo de pensiones, a una de las empresas que conforma el sistema de las AFP. Ante esto, surge la pregunta: ¿Qué son los fondos de pensiones? Según Cardenal Caro Arica ${ }^{11}$, los fondos de pensiones son patrimonios, sin personalidad jurídica propia, formados por el conjunto de aportaciones de los partícipes más todos los rendimientos generados (es decir, más el resultado de las inversiones atribuibles a dichas aportaciones, deduciendo los gastos que le sean imputables). En este punto subyace la pérdida de poder de negociación y reclamaciones de los trabajadores del país. En este punto es necesario que el Estado reconozca el "derecho de la masa", lo cual significa el derecho reconocido y representado jurídicamente por un comité de aportantes que represente el derecho de los ahorristas en la alta dirección de la AFP.

Surge en el trabajador peruano la interrogante sobre por qué el Estado obliga a ahorrar en empresas que permite que se creen con estricto carácter monopólico, o si se quiere un monopolio disfrazado de oligopolio, mediante el cual beneficia a un grupo de empresarios, aun cuando tenemos un sistema financiero libre en el país donde el ciudadano puede ahorrar para su vejez libremente. En todo caso, si él estado quisiera, podría pedirle al ciudadano que entregue a la Sunat, cada año, una declaración jurada sobre la tenencia de sus propios ahorros previsionales en una de la múltiples empresas financieras del sistema, o, en su defecto podría ser un certificado que le pudiera entregar anualmente la entidad financiera. Esta forma permitiría al ciudadano demostrar que ahorra y se preocupa por su retiro o jubilación, y que goza de la libertad de usar sus ahorros ante cualquier imponderable que se le presente en el transcurso de su vida, sea esto por razones de salud, falta de trabajo, inversión en estudios para su progreso u otras razones. El estado, en una país de libre economía, no puede ser contradictorio en la libertad de las decisiones financieras del ciudadano; más aún, el Estado no puede ser coercitivo dado que somos un país en democracia. El Gobierno está en la obligación de pronunciarse si vivimos o no en democracia y si el Estado respeta o no la propiedad privada, como son los ahorros del trabajador.

Asimismo, el Estado cae en contradicciones terriblemente estúpidas, como considerar que el ciudadano es incapaz de darse cuenta de que debe ahorrar para cualquier eventualidad y, desde luego, para su vida en situaciones futuras de edad no productiva. En función de estos criterios, obliga al ciudadano a ahorrar en empresas especialmente creadas para ello y permite que el ciudadano ponga en riesgo dicho intangible, invirtiéndolos bajo el pretexto de hacer rendir más sus ahorros para tener mejor monto de devolución de sus ahorros y rendimientos. Esos riesgos no los debe correr el ahorrista, esos riesgos son de la AFP; sin embargo, el Estado acepta semejante aberración social financiera al permitirle al ciudadano que arriesgue y pueda perder buena parte de sus ahorros.

Otra preocupación del ahorrista es cómo protegerse, en un mundo globalizado, de las calamidades económicas que se importan y afectan las economías de los países, como la crisis financiero económica producida en EE.UU. y trasladada al mundo entero, como sucedió en Argentina. Del mismo modo, los trabajadores ahorristas se preguntan qué garantiza a los trabajadores ahorristas peruanos que no habrá gobiernos que descalabren nuestra economía y de ese modo licuen el valor

11 Cardenal Caro Arica.fondosdepensiones@gmail.com 
de nuestros dineros ahorrados. Qué nos garantiza, como ahorristas, que no tendremos gobiernos que producirán niveles de inflación interna que harán desaparecer nuestro ahorros de aquí a 10, 20 o 30 años y terminemos como ahorristas sumidos en la más grande miseria.

El Estado peruano, y sus sucesivos gobiernos, en estas últimas décadas, es visto por el ciudadano como un ente superior no creíble, corrupto, usurpador de derechos del pueblo; se le ve como un ente ineficiente, abusivo y explotador que grava al pueblo con impuestos y multas excesivas a los que menos ganan y tienen, encareciendo el nivel de vida de los ciudadanos y generador de mayor pobreza. Mientras que el Estado es genuflexo, obediente y callado con el gran capital, y lo premia entregando al pueblo usuario, consumidor, trabajador y tributario a los voraces apetitos de la rápida rentabilidad del gran capital extranjero y nacional y sus monopolios. Estos aspectos políticos y sociales de la alianza del gran capital con el Estado son totalmente negativos para la credibilidad del sistema privado de pensiones por parte de los trabajadores.

\section{EL PROBLEMA}

Gran mayoría de jóvenes trabajadores del país, menores de cuarenta años, no saben que ahorrarán de modo obligatorio y coercitivo un porcentaje significativo de sus ingresos en el sistema privado de pensiones de las AFP por tres o cuatro décadas, y al jubilarse tendrán una devolución mensual de sus ahorros que equivaldrá al $35 \%$ de su último sueldo. Con esta devolución de ahorros, el ciudadano se empobrecerá automáticamente.

\section{OBJETIVO GENERAL DE LA INVESTIGACIÓN}

La investigación pretende advertir que, en Perú, se están presentando los mismos problemas de rechazo de la población trabajadora hacia el sistema privado de pensiones como en otros países de la región sudamericana, por considerar que el sistema es injusto, coercitivo, inquisidor, anti democrático y abusivo, que perjudica fuertemente en aspectos económicos al trabajador, en razón a que no ha dado los resultados ofrecidos a los trabajadores, hace más de veinte años, y hoy reciben la devolución de su dinero después de décadas de ahorro personal, y ven, más bien, que este ha servido para enriquecer determinados grupos de interés económico y político. En virtud de ello la investigación, se plantearon los siguientes objetivos.

\section{OBJETIVO GENERAL}

Corroborar que los ahorristas del Sistema Privado de Pensiones, al momento de su jubilación, recibirán la devolución de sus ahorros mediante mensualidades monetarias cuyos montos los empobrecerán fuertemente.

\section{OBJETIVOS ESPECÍFICOS}

Las AFP, en su esencia funcional, no contienen el concepto de previsión social que debe tener el Estado.

Demostrar que los trabajadores del país consideran injusto el sistema de ahorro impuesto por el Estado.

\section{JUSTIFICACIÓN}

Al culminar la segunda fase de la investigación, se tendrá de manera global razones comunes al pensar y sentir de los trabajadores peruanos y sus pares chilenos, argentinos, colombianos y bolivianos: que el sistema es común en todos los países en los que se ha aplicado y la única forma con la que puede operar este sistema es bajo un modelo coercitivo, en el que la persona pierde su libertad $\mathrm{y}$ derecho sobre la propiedad de sus ingresos y su libre disponibilidad. Se explicará y pondrá en evidencia las razones por las que cuarenta millones de sudamericanos no están de acuerdo con el modelo de administración de los fondos de ahorro de los trabajadores. Se demostrará que el sistema es falso en su esencia social previsional, toda vez que el sistema permite que parte del intangible previsional se arriesgue con el propósito de obtener mayor beneficio de rendimiento por el trabajador, sin que la administradora corra el riesgo que a ella realmente le corresponde, pues el ahorrista entrega su dinero para que estas empresas lo hagan producir. De igual forma, permitirá demostrar que no es justo que a quien se le entrega dinero para que lo trabaje y reditúe beneficios financieros, tenga que cobrar comisiones al ahorrista. De manera análoga, es como que una persona acuda a un banco a depositar su dinero a plazo fijo por una o dos décadas y el banco le cobre una comisión por su depósito. Considero que, de las utilidades que obtienen las AFP, deberán ir devolviendo esos cobros indebidos con sus respectivos intereses a los ahorristas. Al 
culminar la segunda fase de la investigación, tendremos suficientes elementos de juicio que permitirán abrir una discusión con el Estado sobre el tema para la modificación de este problema social del ahorro forzado exigido a los trabajadores por el Estado.

\section{HIPÓTESIS}

\section{HIPÓTESIS GENERAL}

El ahorro de los trabajadores en el sistema de las Administradoras del Fondo de Pensiones les producirá, al momento de su jubilación, un significativo empobrecimiento en relación con sus ingresos remunerativos obtenidos en su etapa productiva.

\section{HIPÓTESIS ESPECÍFICA}

HE1.- El ahorro de los trabajadores en las AFP es confiscatorio y, como tal, no coadyuva al trabajador en su desarrollo humano y familiar sostenible; por el contrario, lo desampara totalmente.

HE2.- El sistema de administración de los fondos de pensiones implantado por el Estado a los trabajadores no contiene y se aparta de los principios fundamentales de la previsión social.

\section{MÉTODO}

La investigación es de tipo exploratoria descriptiva con uso de submétodos cuali - cuantitativos. En su condición de cualitativa, busca encontrar razones por las que el sistema de ahorro es considerado por los trabajadores como injusto y coercitivo. En el aspecto cuantitativo, el método muestral utilizado pretende cuantificar y priorizar las razones por las que los ciudadanos trabajadores del país rechazan el sistema con el cual el Estado los coacciona para que ahorren, privándolos de sus derechos sobre su dinero ahorrado a lo largo de toda su vida y permite a quienes administran sus dineros que impongan al ahorrista las condiciones que a ellos les plazcan y deseen para su devolución.

\section{POBLACIÓN}

La población estudiada en la investigación ha sido hombres y mujeres que pertenecen a la PEA ocupada y menores de cuarenta años de Lima.

\section{LA MUESTRA}

Se utilizó la fórmula de la Universidad de Harvard para la determinación del tamaño de muestra. El nivel de confiabilidad seleccionado para el estudio ha sido de $95.5 \%$, dentro del caso más desfavorable y con un margen de error de $2.239 \%$ sobre los resultados muestrales. Sobre la base de estos datos, se determinó un tamaño de muestra de 2,000 encuestas.

\section{TRABAJO DE CAMPO}

Se seleccionó y capacitó a 105 alumnos de la Facultad de Ciencias Administrativas sobre la identificación de las UEI y manejo del cuestionario para la entrevista. La aplicación del cuestionario se realizó en centros de trabajo del sector privado ubicados en Lima, incluyendo a distritos de Lima norte y sur. El trabajo fue supervisado por un equipo de alumnos del quinto ciclo de la Escuela Académico Profesional de Administración de la FCA, bajo dirección y control del suscrito.

\section{RESULTADOS A PRIORI QUE MARCAN TENDENCIAS HALLADAS EN EL TRABAJO DE CAMPO*}

\section{CUADRO № 1}

Considera usted que el ahorro obligatorio a la AFP impuesto por el Estado es:

\begin{tabular}{|c|c|}
\hline JUSTO & INJUSTO \\
\hline $48 \%$ & $52 \%$ \\
\hline
\end{tabular}

Fuente: Elaboración propia.- Tendencia presentada sobre la base de 200* encuestas.

Como apreciará el lector en el cuadro $\mathrm{N}^{0} 1$, de 200 encuestas tabuladas se ha obtenido una tendencia a priori del $48 \%$ (96) personas que consideraron el ahorro impuesto por el Estado es justo. De otro lado, $52 \%$ (104) personas entrevistadas lo consideraron injusto

\section{CUADRO № 2}

\begin{tabular}{|c|c|c|}
\hline \multicolumn{2}{|c|}{$\begin{array}{c}\text { ¿Por qué razones lo considera JUSTO? } \\
\text { BASE } 96\end{array}$} & PORCENTAJE \\
\hline 1 & $\begin{array}{c}\text { Porque ahorro, y porque muchas } \\
\text { personas no se preocupan de su } \\
\text { vejez }\end{array}$ & $83 \%$ \\
\hline 2 & $\begin{array}{l}\text { Me devolverán mis ahorros } \\
\text { porque así manda la ley }\end{array}$ & $12 \%$ \\
\hline 3 & Otras razones & $10 \%$ \\
\hline \multicolumn{3}{|c|}{ TOTAL : Sobrepasa el $100 \%$ por ser pregunta abierta } \\
\hline
\end{tabular}


El cuadro No 2 está estructurado sobre la base de la pregunta: ¿Por qué razones lo considera JUSTO? En él se muestra alta tendencia, $83 \%$ de las personas entrevistas consideran que es algo justo ahorrar con cierta obligación para la vejez pues muchas personas no lo hacen y luego tienen muchos problemas económicos. El $12 \%$ considera que los ahorros le serán devueltos porque están garantizados por la ley.

\section{CUADRO № 3}

\begin{tabular}{|c|c|c|}
\hline \multicolumn{3}{|c|}{ ¿Por qué razones lo considera INJUSTO? BASE 104} \\
PORCENTAJE
\end{tabular}

Fuente: Elaboración propia, tendencia presentada sobre la base de 200 encuestas $-52 \%$ de ellas consideraron INJUSTO el ahorro obligatorio.

El cuadro $\mathrm{N}^{\circ} 3$ está estructurado sobre la base del $88 \%$ de las personas que consideraron INJUSTO el ahorro por ser obligatorio y coercitivo; debería ser facultativo. El $11 \%$ manifestó que eso les origina una disminución de sus ingresos por sus sueldos. De igual forma, 12 \% opinó que al finalizar sus años de aporte de sus ahorros forzosos, deberían devolver todos los ahorros dado que no es justo que devuelvan como ellos quieran, eso es injusto en cualquier parte y país del mundo. El 16\% quiere la devolución de todo su aporte al momento de su jubilación, para disponer libremente de su dinero.

\section{DISCUSIÓN}

En Perú, como en otros países de Sudamérica, a pesar de encontrarse bajo connotación política internacional de denominación democrática, la ley del Sistema Privado de Pensiones se dio sin la debida participación y consulta a organizaciones de base social laboral por el Estado, en buena cuenta, la ley se impuso que de la misma manera que se hizo posteriormente en Argentina y del mismo modo que en Chile. El sistema privado de pensiones es un modelo de negocio oligopólico, impuesto a los trabajadores por el Estado y ha gozado de la preservación del modelo a través de los sucesivos gobiernos, beneficiándose el Estado, las AFP, el sistema financiero, y la peor parte en relación con los "beneficios" se la han llevado los ahorristas.

La tendencia de consideración como sistema de ahorro injusto por el trabajador peruano es significativamente alta al superar más de $50 \%$ de la empleocracia en Lima.

Los trabajadores consideran que sí es bueno ahorrar para cuando tengan que retirarse por encontrarse en edad de retiro.

Un altísimo porcentaje del $88 \%$ marca una tendencia muy fuerte al considerar el sistema de ahorro impuesto por el Estado como injusto, confiscatorio y antidemocrático, en el que la persona pierde todo derecho sobre su dinero.

Esta etapa de la investigación nos ha advertido que, en nuestro país, ya tenemos serios problemas con las expectativas ciudadanas en relación con el ahorro de los trabajadores en el sistema privado de pensiones, lo cual necesariamente llevará al tratamiento de este sistema para su reforma y obtención de mejores resultados para la fuerza trabajadora del país.

\section{CONCLUSIONES}

La problemática legal, económica, social y política que se vive en Perú es similar a la vivida en Argentina y Colombia. Situación en la que los ahorristas no están conformes con el trato que les brinda la ley del sistema de administración del fondo de pensiones.

Los trabajadores ahorristas, en alto porcentaje, consideran injusto el Decreto Ley 25897.

\section{REFERENCIAS BIBLIOGRÁFICAS}

Friedman, Milton (1976) ¿Qué es la seguridad social? Economía política internacional con ejemplos de América Latina. Premio Nobel en economía 1976 - Viena.

La piedra angular del modelo concentrador de riqueza en Chile (2011). www.elmostrador.clr.cl

Los problemas y soluciones para el sistema previsional en Chile (2013). CNN en Chile. www. cnnChile.com 
AFPs Ganan casi cinco veces más de lo rentan los fondos de pensiones. (2012) www.elmostradormercados.cl

La marcha de los bastones (2011) https:// https://es-es.facebook.com/notes/jorgegómez.../10151079786195489 mbermudezhttp://blog.pucp.edu.pe/member/817/ blogid/741

CLAVIJO VERGARA, SERGIO (2008). Especial para Diario del Huila. Colombia
ZAMINO, DANIELLA (2007). Diario El Mercurio. Chile 23 de Abril del mismo año.

Arrieta Mendoza, Cristina Isabel (2011) Las reformas del sistema pensional colombiano. Colombia- Diciembre 2011.

http://blog.pucp.edu.pe/member/817/blogid/741 http://blog.pucp.edu.pe/member/817/blogid/741

ttp://blog.pucp.edu.pe/member/817/blogid/741 